\title{
DESIGN, QUALIFICATION AND OPERATION OF NUCLEAR ROCKETS FOR SAFE MARS MISSIONS
}

\author{
David Buden, Warren W. Madsen, and Timothy S. Olson \\ Idaho National Engineering Laboratory \\ P.O. Box 1625 \\ Idaho Falls, ID 83415-3413 \\ (208) $526-2661$ \\ Lawrence R. Redd \\ Department of Energy, Office of Space \\ Idaho Field Office \\ Idaho Falls, ID 83402
}

(208) $526-5288$

\section{DISCLAIMER}

\begin{abstract}
This report was prepared as an account of work sponsored by an agency of the United States Government. Neither the United States Government nor any agency thereof, nor any of their employees, makes any warranty, express or implied, or assumes any legal liability or responsibility for the accuracy, completeness, or usefulness of any information, apparatus, product, or process disclosed, or represents that its use would not infringe privately owned rights. Reference herein to any specific commercial product, process, or service by trade name, trademark, manufacturer, or otherwise does not necessarily constitute or imply its endorsement, recommendation, or favoring by the United States Government or any agency thereof. The views and opinions of authors expressed herein do not necessarily state or reflect those of the United States Government or any agency thereof.
\end{abstract}

\section{CAMERA READY MANUSCRIPT prepared for:}

Tenth Symposium

on Space Nuclear Power and Propulsion

Albuquerque, New Mexico

10-14 January 1993

final submission:

Author to whom correspondence should be sent: David Buden 


\title{
DESIGN, QUALIFICATION AND OPERATION OF NUCLEAR ROCKETS FOR SAFE MARS MISSIONS
}

\author{
Idaho National Engineering Laboratory \\ P.O. Box 1625 \\ Idaho Falls, ID 83415-3413 \\ (208) 526-2661David Buden, Warren W. Madsen, \\ and Timothy S. Olson
}

\author{
Lawrence R. Redd \\ Department of Energy, Office of Space \\ Idaho Field Office \\ Idaho Falls, ID 83402
}

(208) $526-5288$

\begin{abstract}
Nuclear thermal propulsion modules planned for use on crew missions to Mars improve mission reliability and overall safety of the mission. This, as well as all other systems, are greatly enhanced if the system specifications take into account safety from design initiation, and operational considerations are well thought through and applied. For instance, the use of multiple engines in the propulsion module can lead to very high system safety and reliability. Operational safety enhancements may include: the use of multiple perigee burns, thus allowing time to ensure that all systems are functioning properly prior to departure from Earth orbit; the ability to perform all other parts of the mission in a degraded mode with little or no degradation of the mission; and the safe disposal of the nuclear propulsion module in a heliocentric orbit out of the ecliptic plane. The standards used to qualify nuclear rockets are one of the main cost drivers of the program. Concepts and systems that minimize cost and risk will rely on use of the element and component levels to demonstrate technology readiness and validation. Subsystem or systems testing then is only needed for verification of performance. Also, these will be the safest concepts because they will be more thoroughly understood and the safety margins will be well established and confirmed by tests.
\end{abstract}

\section{INTRODUCTION}

Performing a Mars mission safely involves getting the crew there and back in good physical and mental condition. Nuclear thermal propulsion was selected for this mission because of its high specific impulse, resulting in faster trip times for all opportunities with much reduced propellant requirements, minimization of any spacecraft assembly needed in Earth orbit, and increase in the windows of opportunity for going to and from Mars. From a safety viewpoint, the implications are: reduced crew exposure to galactic radiation, reduced psychological and physiological stresses to the crew, less chance of leaving Earth orbit for Mars without a spacecraft thoroughly checked out and less chance of troubles in assembling the spacecraft prior to leaving Earth orbit.

The design and operational considerations of propulsion module safety are summarized in the goal tree shown as Figure1. The key element under having thrust available when needed is to be sure that propellant is retained in the tank over the long mission times of several years. The ability to control thrust vectoring has been demonstrated many times in lung space missions with repeated success. Power only. when needed ensures that the reactor is operational only at the times specified by the spacecraft master controller. In addition, safety is related to the development and qualification of the engine systems. If the engine capabilities are not thoroughly understood with its design margins clearly known, the safety of the crew and mission is jeopardized.

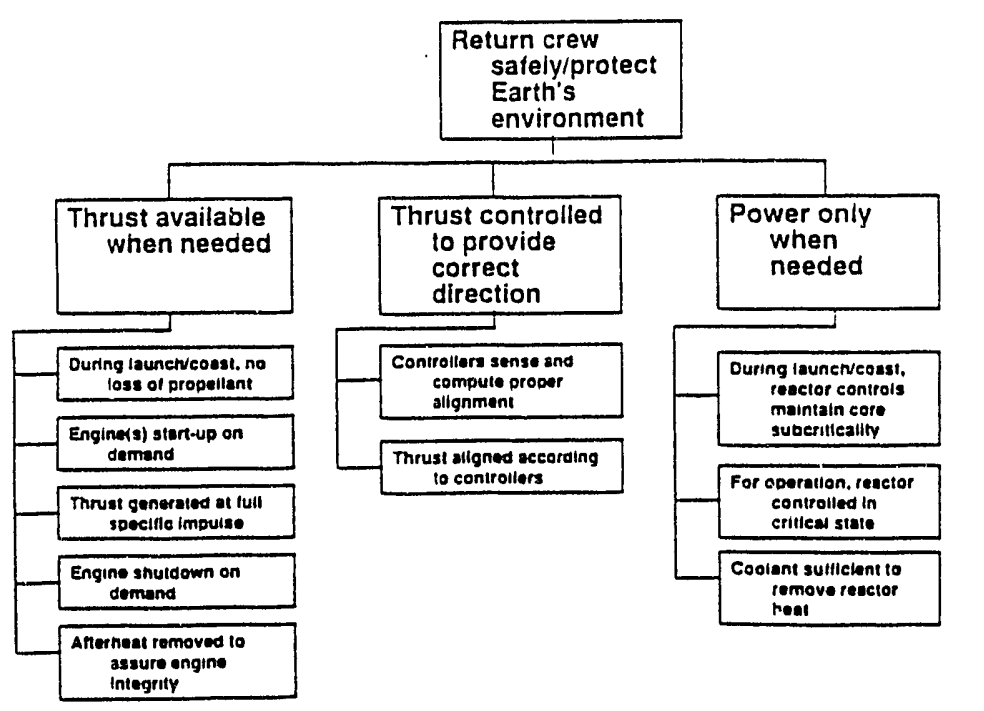

Figure 1. Goal Tree For Nuclear Stage 
PROPULSION MODULE SAFETY CONSIDERATIONS

The propulsion module must operate throughout all segments of the mission. Therefore, safety considerations are essential in defining the elements of the propulsion module. Though safety is thought of in terms of assuring the return to Earth of the crew in a healthy condition, it can be quantified in :eliability terms. A number of arrangements were analyzed, including both single and multiple engines, and considered with and without redundant active elements. Figure 2 shows one such arrangement from the NERVA development program. With a single failure of an active element, the engine would continue to operate. TheNERVA engine was being designed for a mission reliability of 0.995 . Triple redundancy was analyzed; however, the passive elements were found to dominate the reliability, and the engine reliability was not any higher than that for dual redundancy. Figure 3 shows a configuration with three engines, but no active element redundancy within a given engine. There are redundant valves from the tank to avoid loss of propellant from a leaking valve. Figure 4 shows the effect of engine number on mission success and safe return of the crew. NERVA engine reliability values were used in the analysis. These were then degraded by a factor of ten to see the effect of 0.95 mission reliability for each engine. Figure 4 shows the results of adding more engines, but does not take into account common cause and nonindependent failures.

Common cause and nonindependent failures were then examined. Common cause failures relate to conditional failures given a failure of one component where identical components are present elsewhere in the propulsion module. The commercial nuclear power plant industry has found that other models of that component will fail at an increased rate. Generic values used are to increase the failure rate for the second component by 0.1 , and for a third component by 0.5 . However, these values can be reduced by strict quality control standards, independent inspection of all operations, and detailed understanding of the designs. These standards apply to space systems and certainly must be instituted for the propulsion module. The common cause values can than be reduced to about 0.1 and 0.3 respectively. If strict quality standards are not applied, redundancy buys very little; with strict standards, redundancy significantly increases the propulsion module reliability (based on the same failure rate for each element').

A nonindependent failure is a failure that causes one or more additional failures. Nonindependent failures that are catastrophic to the mission/crew are much less likely for nuclear rockets than occur with chemical rockets. This
Figure 2 Single Engine High Reliability Drives towards Redundant Active Components (single engine - fail safe)

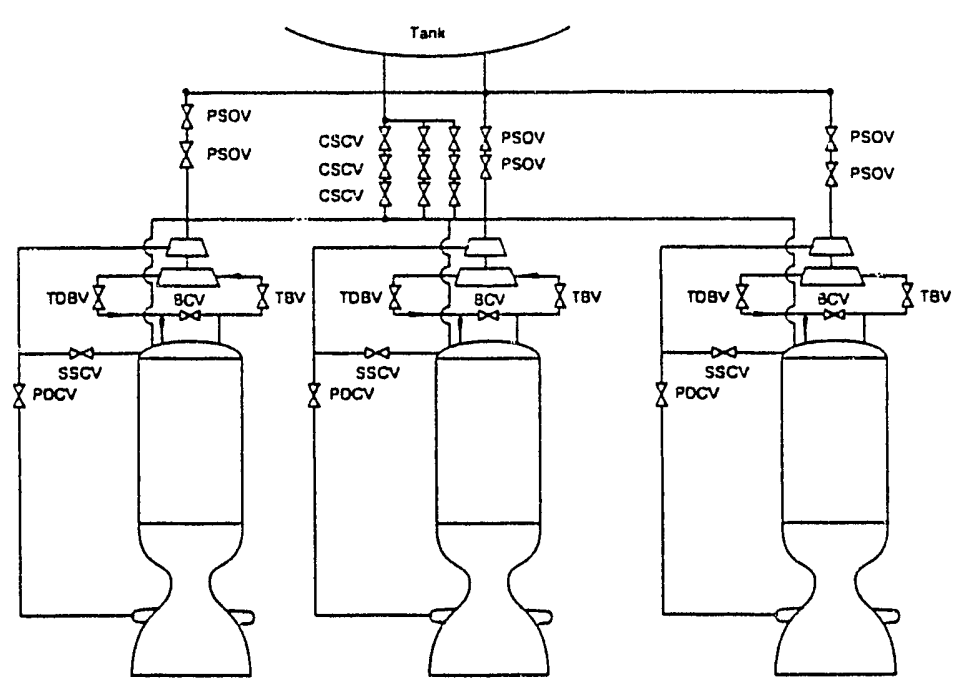

Figure 3. Clustered Engines Drives toward Simpler Engines and High Propulsion Module Reliability (clustered engines (3) - fail operational/fail safe) 
is a result of having only a monopropellant present and less energetic urbomachinery. The most significant

nonindependent failure of concern is the destruction of the turbopump, with energy on the order of 10,000 hp at design operations. This energy could be released by unloading the pump, perhaps by excess operation at a critical speed or by a high head, low flow condition resulting in vapor generation along the impeller. The turbopump needs to be designed and oriented to auger away from other engines and propellant tanks. Another potential nonindependent failure sometimes considered is a meltdown of one reactor in a redundant propulsion module. Experience in the ROVER program, where a complete loss of flow occurred, was that the reactor containment vessel remained intact. In addition, an emergency cooldown tank, pressurized off of pump discharge pressure, can be used to handle both emergency and normal cooldown situations.

Interactions between clustered engines include neutronic coupling, shutdown core power generation, shutdown reactivity, and reactor kinetics and control. Experiments, called KIWI-PARKA, were run in the 1960's on coupling at Los Alamos National Laboratory and calculation models used to predict the extent of the reactor coupling (Buksa 1992) (see Figure 5). The results show that the coupling reactivity between cores is small and is inversely proportional to separation distance and to core size. One unwanted consequence of neutronic coupling is the subcritical fission power generated in an engine-out situation. Even though the shutdown reactor is far from critical, the nearby operating engines act as a relatively significant source of neutrons, which can undergo multiplication and thus produce power. The driver core leakage term scales linearly with power level and the geometric term between cores varies litule for constant core separation distances. Table 1 (Buksa 1992) shows the cluster shutdown engine heat generation rates resulting from decay power and neutronic coupling to adjacent operating engines. The pulse cooling decay heat system should be adequate to handle this coupling power since the coupling power is less than the decay heat power. Reactor kinetics and control are not major problems. The control systems will probably use temperature control with overrides to protect against excessive fuel temperatures.

TABLE 1. Cluster Shutdown Engine Heat Generation Rates resulting from Decay Power and Neutronic Coupling to Adjacent Operating Engines

\begin{tabular}{|c|c|c|c|c|}
\hline \multirow[b]{2}{*}{$\begin{array}{l}\text { Nominal Engine } \\
\text { Power Level (MW) } \\
\end{array}$} & \multirow[b]{2}{*}{$\begin{array}{l}\text { Maximum Decay } \\
\text { Power Level (MW) }\end{array}$} & \multicolumn{3}{|c|}{ Power Level in Single Shutdown Coupled Core (MW) } \\
\hline & & $\begin{array}{l}\text { Shutdown }{ }^{b}= \\
\$ 2\end{array}$ & $\$ 4$ & $\$ 25$ \\
\hline 1100 & 44 & $\overline{31} \mathrm{c}$ & $15^{\mathrm{c}}$ & 2.5 \\
\hline $\begin{array}{l}1500 \\
5000\end{array}$ & $\begin{array}{c}60 \\
200\end{array}$ & 41 & $\begin{array}{l}21 \\
60 \mathrm{c}\end{array}$ & $\begin{array}{l}3.3 \\
8.8\end{array}$ \\
\hline
\end{tabular}

aultiply by numnber of active engines in cluster to get toatl heating in shutdown engine

b $\beta=0.007$

c From Mowery and Romesburg 1965 
Safety favors the use of more than one engines. Therefore, multiple engines will be used for the balance of this paper.

\section{OPERATIONAL CONSIDERATIONS}

Operations must be performed in a safe and reliable manner and strongly determines the safety provided to the crew and environment. (see Figure 6)

Multiple perigee kicks have been advocated as a means to reduce the mass in low Earth orbit for low total thrust (Figure 7 illustrates the savings from use of multiple perigee kicks). This approach also has safety implications.

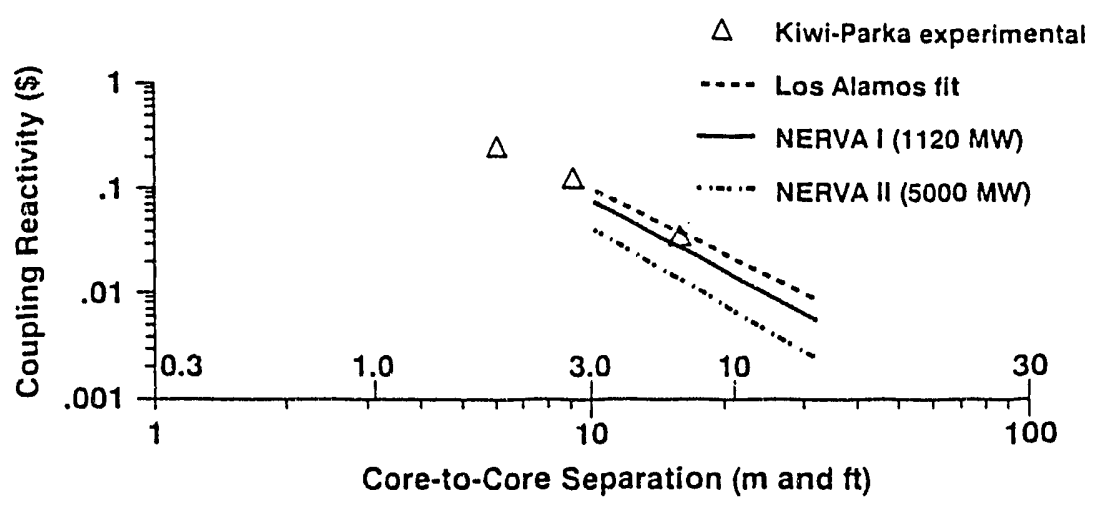

Figure 5. Experimental and Past Analytical Predictions of Coupling Reactivity as a function of Core Separation

First of all, the crew makes additional
passes through the Van Allen belts. The effects from this were quantified and found to add less than 0.2 rem out of some 40 rem projected from natural radiation in a 150 day trip to. Mars. This assumes that the crew is shielded by the equivalent of 6 inches of water (an amount that is conservative compared to what will be needed for a solar flare storm shelter) and that the crew will be in the solar flare storm shelter during the few hours of nuclear propulsion operations. The total time in the Van Allen belts is: 30 minutes for a single bum Trans Mars Injection, 2 hours for a two burn Trans Mars Injection, and 4 hours for a three burn Trans Mars Injection.

Another safety consideration of multiple perigee burns is the time available to assess the performance of the entire spacecraft before the final commitment to leave for the multiyear Mars mission. With a single bum, the time is about one hour, but with three perigee burns there is about 20 hours to assess the functionality of all the onboard systems. This time can be extended by allowing extra orbits between burns for checking equipment.

Thrust misalignment is also an operational concern. However, studies show that the thrust misalignment would need to go undetected for very long periods of time to become a significant hazard to the Earth. Figure 8 illustrates this point; a five minute bum at perigee with a 50 degree misalignment of thrust from the propulsion module would result in only a $30 \mathrm{~km}$ loss of perigee altitude. Therefore, thrust misalignment is not a safety problem.

Disposal

- Separate from ECCV

- Final midcourse

- Disposal location

- Earth impact probability

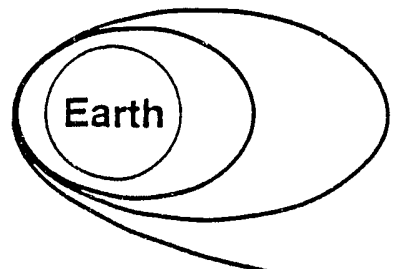

Trans-Earth insertion

- Degraded operation (Isp and thrust)

- Return time penalties

- Midcourse with low thrust

Multiple Perigee kicks

- Lower thrust (longer burn time)

- Plane change at Apogee

- Failure tolerance and mission commit philosophy

- Throttling to $5 \%$ (cooling, Xenon, and perigee raising?

- Van Allen Belts
Mars capiure

- Rendezvous with high reliability and throttling

- Incurred system failures and mission commit

- Lower thrust required than near-earth

- Mars flyby/powered abort

\section{-}

U92 0448

Figure 6 Clustered, Low-Thrust Engines Foster Mission Success 
Midcourse corrections require only a small amount of thrust. This can be accurately accomplished by operating only one engine. At Mars, capture can be achieved with only two out of four engines operational. This provides great flexibility and reliability in safely completing this part of the mission. If for some reason the mission must be aborted, a powered flyby of Mars can be performed and the spacecraft can be placed on an Earth return path with less than full thrust, specific impulse or propellant mass.

A nuclear rocket propulsion module that can operate in degraded modes, that is one with less than full thrust, specific impulse, or even with some loss of propellant significantly adds to the safe return of the crew to Earth. TransEarth insertion can be achieved with degraded operations of both specific impulse and thrust. Regarding thrust, only one out of four engines is needed to return home. Degraded performance was evaluated assuming the trip times back to Earth are increased or more propellant is carried. The penalties (see Figures 9 and 10) are quite small, with a ten day trip extension with the loss of three out of four engines. Thus, the probability of successful retum even in a degraded condition is very high.

Disposal can be performed following the final midcourse correction half way out. The propulsion system is already out of the plane of the ecliptic, and thus is aligned to miss Earth due to the return from Mars in a nonecliptic plane. A mean time between encounter of the spent stage and the Earth has been calculated to be approximately 10 million years with nonpropulsive disposal (Stancati 1991). Fission product decay occurs in about 300 years. Propulsive disposal of engines was calculated, with the conclusion that the penalty of additional propellant mass of at least half the engine mass did not warrant the additional lifetime extension.

\section{QUALIFICATION OF A NUCLEAR ROCKET}

There is no definitive guide on qualification of a nuclear thermal rocket. The Defense Department uses MILSTD 1540B, but it is left to the program to interpret what testing and analysis is needed for each phase. The content of MIL-STD 1540B is summarized in Figure 11. The key elements in each phase are shown.

Nuclear propulsion qualification can be achieved at various complexity levels (see Figure 12). It is important to select concepts where the major uncertainties in the designs can be qualified at the most basic levels. Engineering 
experience shows that the cost of qualifying at the next level goes up by a factor of approximately ten. Thus, concepts that have most of the uncertainties resolved at the lowest (materials or elements) level will lead to programs that can be better scheduled and cost significantly less. Safety is also enhanced because the design margins will be known and determined early in the program; thus the hazards of shortcuts will be reduced.

Table 2 is a summary of significant risk items. All phases of operation must be considered. The highest risk element is the reactor fuel element and its arrangement within the core. Axial, radial, or spherical core arrangements are candidate configurations. Some desirable characteristics are given in Table 3.

The more of these characteristics that are incorporated into a design concept, the lower will be the development cost and the higher the safety.

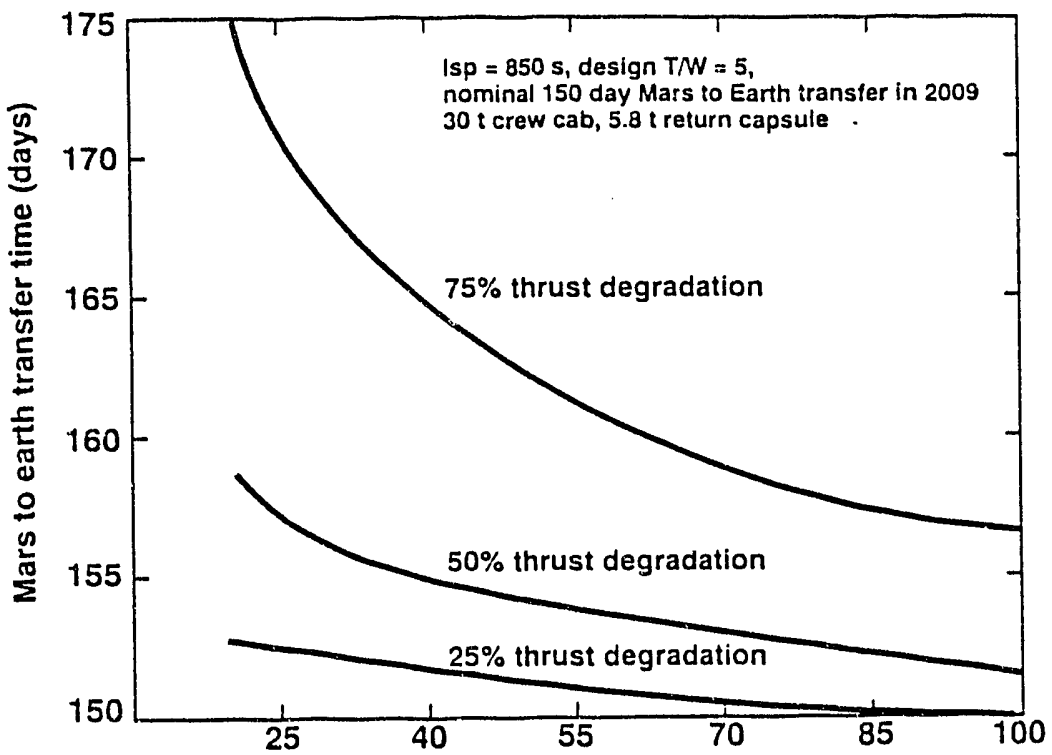

Figure 9. Increased Return Transfer Time From Thrust Degradation $320+42$

TABL.E 2. Significant Risks

\begin{tabular}{cl}
\hline - Overall & - Operation \\
- Meets all specification requirements & - Meets safety goals \\
- Meets burn life times by established factor & - Flow distribution causes hot spots \\
- Launch & - Fuel operating with insufficient margins \\
- Acoustic noise damages structural integrity & - Erosion of fuel elements \\
- Fuel is compacted & - Nozzle bum through \\
- Reactor subcritical in launch abort & - Reliable valve operations \\
- Coast & - Integrity of system after emergency \\
- Leakage from hydrogen tanks & shutdown \\
- Oestart & - Meets throttleability needs \\
- Overspeed or cavitation of turbopump & - Meets overall reliability goals \\
\hline
\end{tabular}

Figure 10 Increased Mass From Trans Earth Injection With Thrust Degradation

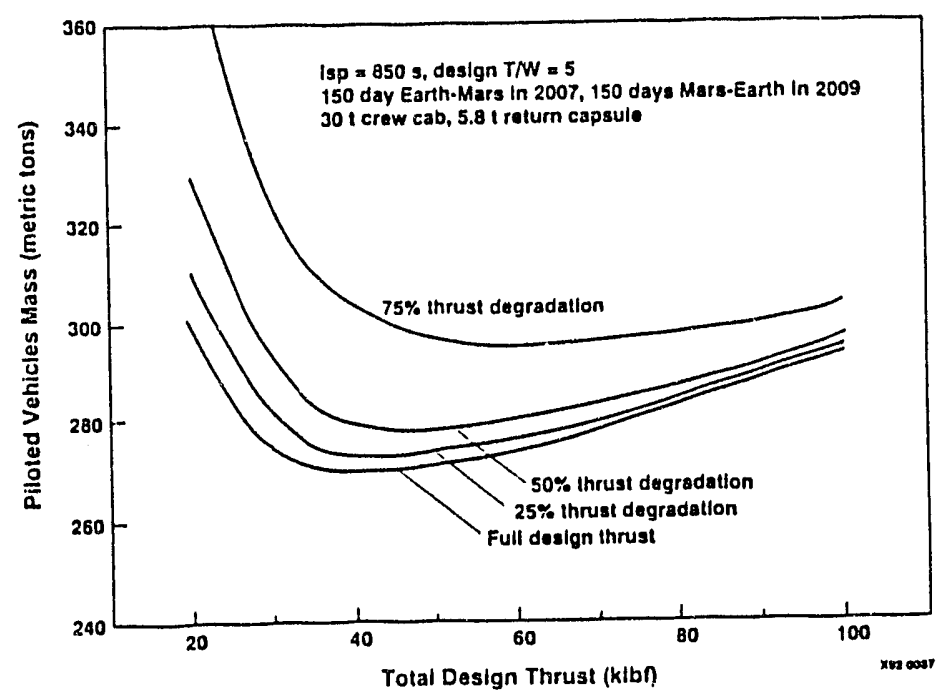


TABLE 3. High Uncertainty Items Resolved at Element/Component Levels

\title{
- Core options
}

$$
\begin{aligned}
& \text { - Axial } \\
& \text { - Radial } \\
& \text { - Spherical }
\end{aligned}
$$

\section{- Some desirable characteristics}

\author{
- Same power into all fuel elements (llatten power axially and radially) \\ - Constant fuel exit temperature \\ - Constant fuel exit pressure \\ - Fuel customized to reactor environments \\ - Simple fuel element support \\ - Controlled flow to each fuel element \\ - Eliminate coolant flow to nozzle and special coolant for elements \\ - Sell-regulated over temperature protection \\ - After heat removal by radiation as soon as possible after shutdown \\ (or switch to radiators) \\ - Highly throttleable at full specific impulse \\ - Passive reactivity control \\ - Emergency cooldown protection \\ - Minimize single failure points and critical components
}

\section{Euel Oualification}

Though all component qualification is vital to the success of the engine development, this paper will concentrate on the fuel elements. Fuel elements are the heart of space nuclear propulsion systems. They are the life and performance limiting element in the engines. As such, fuel qualification will govern the development of nuclear rockets and determine the specific impulse and strongly influsence the thrust-to-weight ratio that can be achieved in

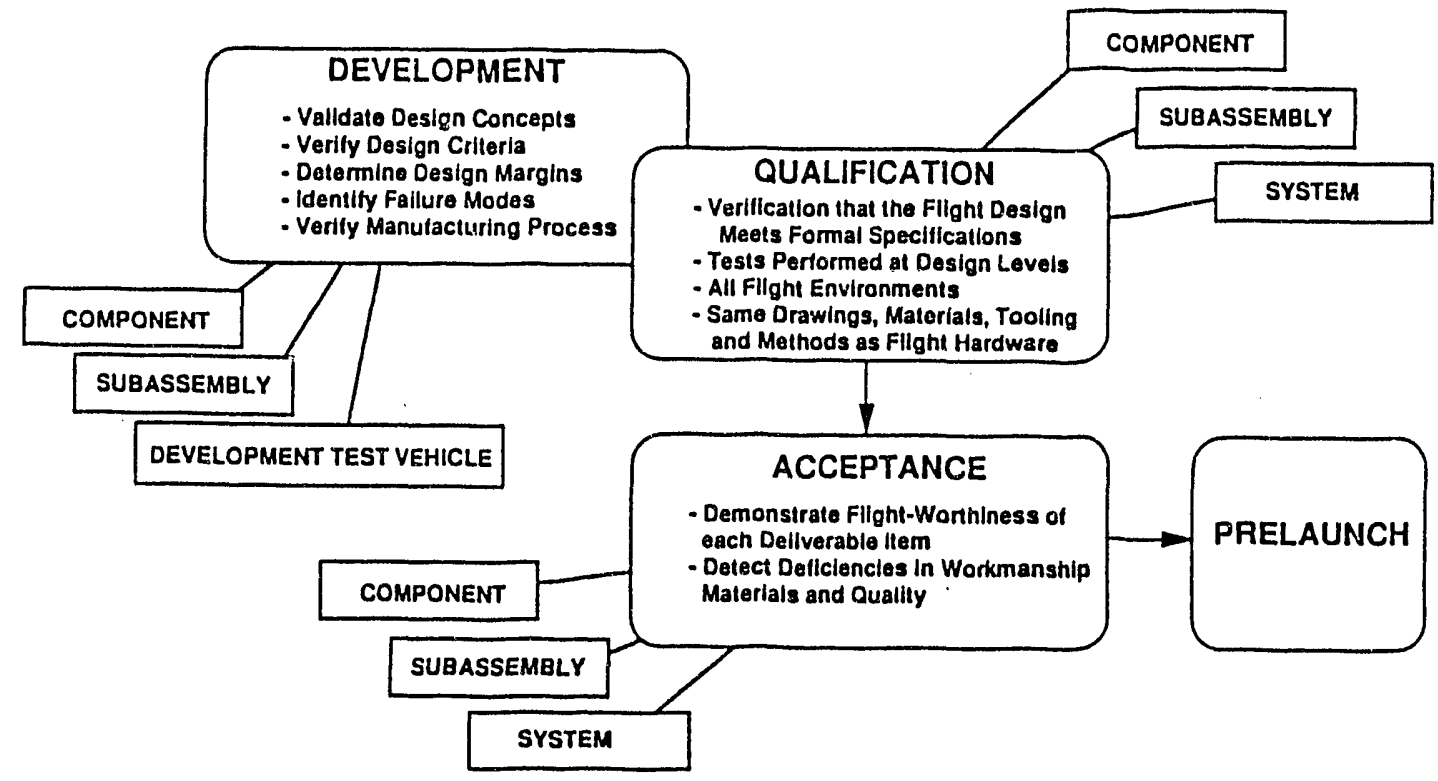

Figure 11. Testing Phases and Assembly Levels defined by ML-STD 1540B 
any engine design. Qualification testing addresses safety, reliability, and performance requirements derived from the mission and program needs, and environmental requirements under normal and accident conditions. The qualification requirements are summarized in the following table.

TABLE 4 Fuel Requirements Qualification

\begin{tabular}{ll}
\hline Euel Performance Requirements & \\
Specific Impulse & Temperature \\
Thrust/Weight & Power Density \\
Burn Time and Life-Time & Life-Time At Temperature \\
Restarts/shutdown & Cycling Capability \\
Propellants & Chemical Compatibility
\end{tabular}

Safety Requirements

Crew and Environment Exposure

Coolable Geometry

Beliability Requirements

Confidence Level and Failure

Probability
Fission Product Retention

Mechanical \& Chemical Integrity
Environmental Requirements

Launch
Properties Data Base

Failure Mechanisms
Gravity forces

Vibration

Acoustics

Fuel qualification strategy is based on qualifying fuel at the lowest possible level, which would correspond to a single fuel element. This is accomplished by: (1) establishing a "pedigreed" data base of material and fuel properties with uncertainties using unirradiated and irradiated test data; (2) determining failure mechanisms using models which are then validated using experiments; (3) resolving feasibility issues to demonstrate that the fuel meets performance specifications; and (4) establishing a reliability and reproducibility data base including demonstrating that the fuel can perform its functions for some multiple of its design specification at full temperature lifetime.

In order to meet the fuel requirements, fuels testing focuses on the following test objectives:

- Resolve technical feasibility issues (life, strength, ... as functions of time),

- Determine safety margins,

- Validate design and operating performance,

- Establish fuel reliability, and

- Verify and validate codes.

To achieve these test objectives, several types of testing are required, including non-nuclear testing, irradiated capsule testing, single element and/or bundle testing and engine testing. A data base for the test results and a method for analyzing these tests need to be established.

\section{Engine Qualification}

The fuel and core components will be integrated into the engine and tested to ensure that they all work together and to validate engine performance. The engine is subjected to launch loads and other environments prior to testing to ensure that these do not adversely affect operations when launched into space. These tests will demonstrate engine lifetimes and performance over the entire engine temperature, power and pressure map. Significant numbers of fuel elements are included in each test. Thus, these tests greatly add to the fuel element data base. These tests also validate that the qualification testing performed at more elementary levels was sufficient to qualify the fuel elements.

The number of engines to be tested is still being determined. Development test articles should be as close as possible to flight articles to avoid design iterations. Both performance behavior over the engine operational regime 
and duration testing at full power will be needed. The test article will probably not be tested to failure in order to avoid contamination of the test facility. In any case, the limited number of tests could not test each failure mode sufficiently. Flight validation tests would be performed on several articles of the final configuration, thereby demonstrating typical flight profiles, performing duration testing at full thrust and specific impulse and showing repeatability between flight articles.

\section{SUMMARY}

Safety can be achieved to protect the environment and crew with proper considerations of design, testing and operations. To assure that the engines are highly reliable, and thus assure crew safety, concepts need to be selected where the key uncertainties in the design can be resolved at element or component levels. This increases the ability to understand and test for design margins. The propulsion module can be made to achieve almost $100 \%$ assurance that it will perform its intended functions. This is achieved with redundant engines that allow a high degree of thrust degradation and still meet mission success and safety criteria. Also, using multiple perigee kicks to escape from low Earth orbit while minimizing gravity losses for a Mars mission can lead to a nuclear thermal rocket size that is applicable to many other missions.

\section{Acknowledgments}

This work was performed under the sponsorship of the U.S. Department of Energy, Idaho Field Office, DOE Contract \#DE-AC07-761D01570. The contents are ideas of the authors and not the official positions of the Department of Energy or National Aeronautics and Space Administration.

\section{References}

Buksa, John J. et al (1992) "Nuclear Thermal Rocket Clustering I: A Summary of Previous Work and Relevant Issues," CONF 920104, American Institute of Physics, pp. 1089-1102.

Stancati, M. L. and A. L. Friedlander (1991) "Disposal Modes for Mars Transfer Nuclear Propulsion," AIAA Paper 91- 3410, AIAANASA/OAI Conference on Advanced SEI Technologies. Cleveland, OH, 4-6 September 1991. 

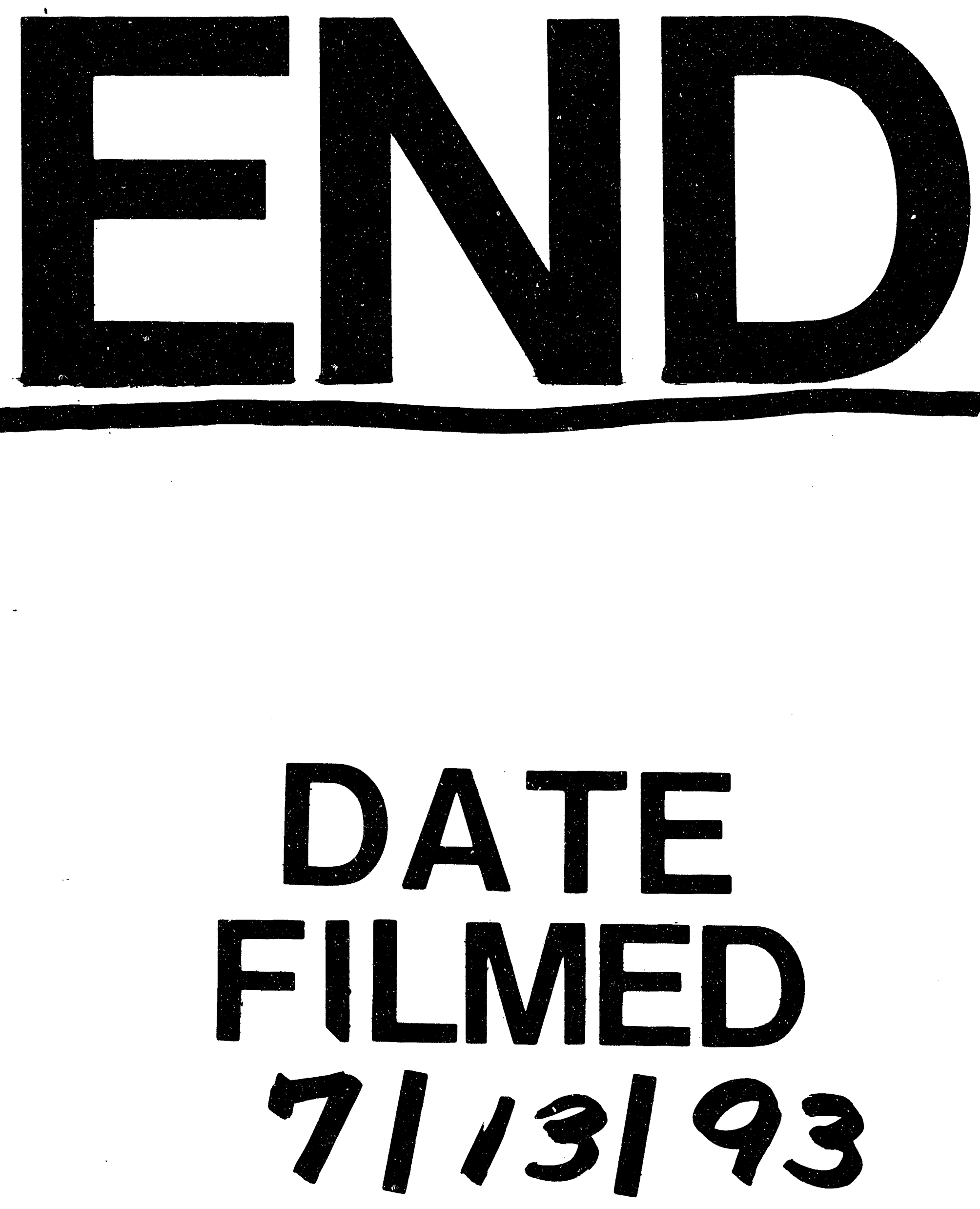


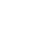

